УДК 582.28:57.082.26+635.24

\title{
КУЛЬТИВИРОВАНИЕ ГРИБОВ РОДА ТRICHODЕRMA НА ВЕГЕТАТИВНОЙ ЧАСТИ ТОПИНАМБУРА
}

\author{
() М.А. Пикозина", Н.А. Чупрова, Т.В. Рязанова \\ Сибирский государственный технологический университет, ул. Мира, 82, \\ Красноярск, 660049 (Россия), e-mail: bioleif@yandex.ru
}

\begin{abstract}
Представлены результаты исследования процесса биоконверсии вегетативной части топинамбура грибами рода Trichoderma asperellum, штаммы «M99/1» и «М99/9». Показано изменение углеводной части топинамбура в процессе биодеструкции. Установлены динамики титра спор и убыли массы, а также целлюлазная активность исследуемых штаммов. Благодаря значительным изменениям в лигноуглеводном комплексе наглядно показана целесообразность использования вегетативной части топинамбура в качестве субстрата для выращивания грибов рода Trichoderma. Полученные результаты также позволили провести сравнительную характеристику двух новых, ранее не исследованных штаммов с целью выявления наиболее активного.

Ключевые слова: вегетативная часть, топинамбур, Trichoderma, биоконверсия.
\end{abstract}

\section{Введение}

Безопасная и максимально практичная переработка растительного сырья в современном мире - безусловно, важная задача. Достижению этих целей давно способствует развитие биотехнологии, которая позволяет с помощью микроорганизмов создать из ненужных, кажется, отходов ценные препараты для сельского хозяйства, медицины, спиртового производства. Так, грибы рода Trichoderma, используя в качестве источника питания растительное сырье, позволяют получить защитные биопрепараты, препятствующие поражению растений корневыми гнилями. Выбирая подходящий для грибов субстрат, необходимо ориентироваться на повышенное содержание в нем сахаров. Полностью отвечает данному условию вегетативная часть топинамбура. Топинамбур - многолетнее травянистое растение высотой от 1,5 до 4 м [1]. В промышленности в основном используются клубни топинамбура, позволяющие получать фруктозные сиропы, инулин, спирт и многое другое [2, 3]. Надземная часть используется значительно реже (чаще в качестве корма для скота). Однако благодаря высокому содержанию сахаров она может стать отличным субстратом для выращивания микромицетов.

Использование вегетативной части топинамбура в качестве субстрата для выращивания грибов рода Trichoderma позволяет решить несколько важных задач. Во-первых, происходит экологичная утилизация растительного сырья. Во-вторых, в ходе такой утилизации получается ценный продукт - защитный биопрепарат, применяемый в сельском хозяйстве.

Таким образом, целью работы стало изучение возможности применения вегетативной части топинамбура в качестве субстрата для грибов рода Trichoderma, а также исследование двух новых штаммов -

Пикозина Мария Александровна - аспирант, тел.: (391) 211-70-54, e-mail: bioleif@ yandex.ru Чупрова Нелли Александровна - кандидат технических наук, доцент, тел.: (391) 211-70-54

Рязанова Татьяна Васильевна - доктор технических наук, профессор, тел.: (391) 211-70-54

e-mail: tatyana-htd09@mail.ru
«М99/1» и «М99/9». Это аборигенные штаммы рода Trichoderma, выделенные из почв Мининского лесопитомника в период 1998-2000 гг. и предоставленные доцентом базовой кафедры биотехнологии Сибирского федерального университета С.В. Прудниковой.

\footnotetext{
* Автор, с которым следует вести переписку.
} 


\section{Экспериментальная часть}

Объектом исследования послужила вегетативная часть топинамбура. Предварительно она была высушена до воздушно-сухого состояния и измельчена на дезинтеграторе до $6^{\circ}$ помола.

В подготовленном таким образом сырье по методам, используемым в химии древесины и химии растительного сырья, был определен химический состав, а именно: содержание минеральных и водорастворимых веществ, легко- и трудногидролизуемых полисахаридов и веществ лигниновой природы [4-5]. В дальнейшем исследованная вегетативная часть топинамбура была использована в качестве субстрата для выращивания грибов рода Trichoderma.

Во всей работе использованы следующие обозначения:

- субстрат 1 - исходный топинамбур;

- субстрат 2 - топинамбур, биодеструктированный штаммом «М99/1»;

- субстрат 3 - топинамбур, биодеструктированный штаммом «М99/9».

В субстрат 1 вносили споры грибов Trichoderma в расчете $1 \cdot 10^{6}$ спор/г а.с.с. Культивирование проводили твердофазным методом в термостате при температуре $27,5-28,5^{\circ} \mathrm{C}$ и начальной влажности субстрата 70-75\%. Продолжительность культивирования составляла 5, 11, 14, 16 сут.

Для выявления наиболее активного из двух штаммов была определена их целлюлолитическая активность. Активность фермента выражают в условных единицах. Единица активности целлюлазы - количество фермента, под действием которого в реакционной смеси образуется 1 мг глюкозы в оптимальных условиях для продуцента (температура $\left.28-30^{\circ} \mathrm{C}, \mathrm{pH} 5,2\right)$ за 30 мин [6].

\section{Обсуждение результатов}

По химическому составу вегетативная часть топинамбура (субстрат 1) представлена лигноуглеводным комплексом, на долю которого приходится около $54,2 \%$, и на $36,7 \%$ веществами, экстрагируемыми горячей водой, которые более чем на половину состоят из веществ сахарной природы (моно- и олигосахаридов). В процессе биоконверсии вегетативной части топинамбура грибами рода T.harzianum (штамм «M99/1») и T. asperellum (штамм «М99/9») наблюдается изменение как массы субстрата, титра спор, так и химического состава.

Важные результаты о развитии грибов дали исследования титра спор и убыли массы. Измерения проводились на 5-е, 9-е, 11-е, 14-е и 16-е сутки.

В течение всего времени культивирования проводили замеры урожая конидиеспор и рассчитывали убыль массы субстратов.

Урожай конидиеспор грибов рода Trichoderma на субстратах топинамбура представлен на рисунке 1.

Уже на 5-е сутки наблюдался сплошной слой спор грибов на всей поверхности субстрата (споры, окрашенные в зеленый цвет, придавали зеленую окраску всей поверхности субстрата), а на 16-е сутки в результате глубокого проникновения гиф в субстрат первоначально рыхлое сырье приобрело комковатую структуру.

К 16-м суткам культивирования происходит замедление роста грибов, об этом говорят показания урожая конидиеспор. Их значения на 14-е сутки практически равны значениям на 16-е сутки, что говорит о замедлении роста штаммов. Поэтому срок культивирования составил 16 суток.

Следует отметить, что, как видно из рисунка 1 , уже к 5-м суткам культивирования урожай конидиеспор обоих штаммов значительно превышает начальный титр засева. Так, для штамма «М99/1» он увеличился в 711 раз, а для штамма «М99/9» только в 630 раз. За первые 5 суток культивирования урожай конидиеспор штамма «М99/1» несколько опережает таковой для штамма «М99/9». Однако уже к 9-м суткам штамм «М99/9» имеет более высокую скорость конидиеобразования, чем штамм «М99/1». Эта закономерность сохраняется в дальнейшем на протяжении всего периода культивирования. К 16-м суткам количество спор штамма «М99/1» увеличилось в 1146 раз, а штамма «М99/9» в 1387 раз.

К 16-м суткам культивирования происходит замедление роста грибов, по-видимому, за счет процесса самоингибирования. Поэтому увеличение срока культивирования более 16 суток не целесообразно.

Наряду с определением титра спор, была рассчитана убыль массы.

Каждый исследуемый субстрат имел номинальную известную массу. В течение всего времени биоконверсии (через $5,9,11,14,16$ суток) производили взвешивание субстратов, которое показало, что их масса в процессе культивирования постепенно снижается. На основании полученных данных рассчитана убыль массы, приведенная на рисунке 2. 


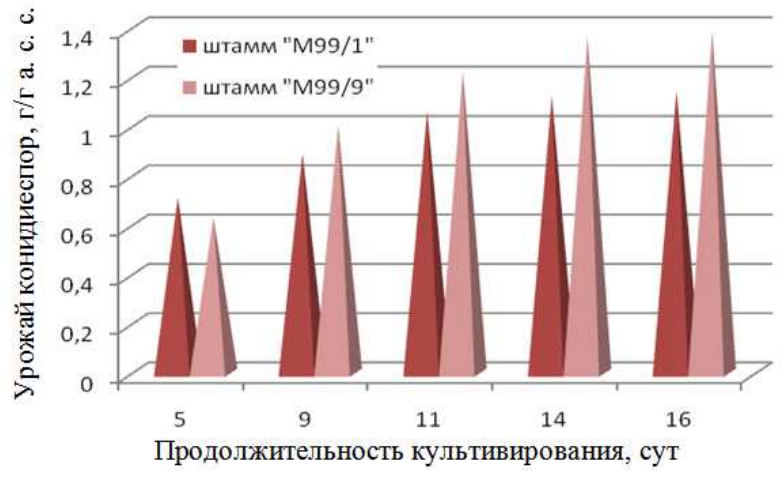

Рис. 1. Динамика урожая конидиеспор

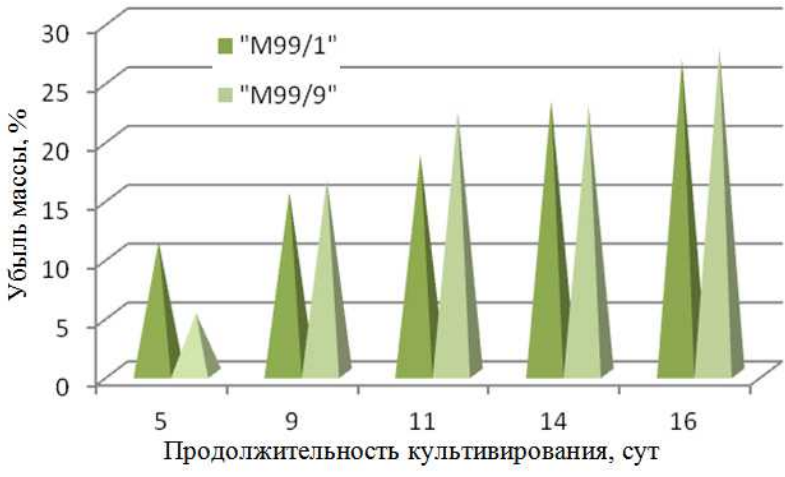

Рис. 2. Динамика убыли массы субстратов

Динамика убыли массы, как видно из рисунка 2, для штаммов «М99/1» и «М99/9» аналогична. Различие заключается только в скорости убыли массы. Так, на 5-е сутки убыль массы штамма «М99/1» составляет 11,2\%. Процент убыли массы для штамма «М99/9» меньше в 2,2 раза и составляет только 5,1\%. Это хорошо согласуется с полученными показаниями урожая конидиеспор. Однако, как видно из рисунка 2, к 9-м суткам штамм «М99/9» имеет более высокую скорость убыли массы, чем штамм «М99/1», по сравнению с 5-ми сутками, и эта закономерность сохраняется до конца культивирования.

Увеличение продолжительности культивирования грибов до 16 суток приводит к монотонному увеличению убыли массы. На 14-е сутки убыль массы субстрата 2 составила 23,2\%, что в 2,1 раза больше, чем на 5-е сутки. Для штамма «М99/9» эти цифры составили соответственно 22,7\% и 4,45 раза.

На 16-е сутки культивирования при незначительном увеличении титра спор по сравнению с 14-ми сутками убыль массы у обоих штаммов составила более $25 \%$ от номинальной массы.

Об эффективности воздействия штамма «М99/1» T. harzianum и штамм «М99/9» T. asperellum на субстрат можно судить по изменению содержания его основных компонентов и убыли массы. Химический состав субстратов после биодеструкции в течение 16 суток представлен в таблице.

Сопоставлением химических составов субстратов после биоконверсии штаммами «М99/1» и «М99/9» видно, что в целом штаммы ведут себя одинаково в процессе биодеструкции.

Для установления изменений, происходящих при биоконверсии сырья, необходимо учитывать убыль массы субстратов.

Основываясь на полученных результатах убыли массы, можно с уверенностью сказать, что изменениям подверглись все вещества растительного сырья. Так, содержание водорастворимых веществ в процессе биодеструкции снижается по сравнению с исходным топинамбуром. К 16-м суткам культивирования их содержание падает для штамма «М99/1» в 1,4 раза, а для штамма «М99/9» - в 1,5 раза. Это, повидимому, объясняется тем, что в первую очередь происходит утилизация моно- и олигосахаридов. Значительно снижается и общее содержание полисахаридов для обоих штаммов (в 1,6 раза), что свидетельствует о наличии у данных штаммов целлюлазной активности.

Количество лигнина в процессе биодеструкции для обоих штаммов уменьшилось в 1,3 раза.

Таким образом, в процессе биоконверсии была утилизирована основная часть лигноуглеводного комплекса вегетативной части топинамбура. Если в исходном топинамбуре на долю лигноуглеводного комплекса приходится более 53\%, то после биодеструкции этот показатель для штаммов «М99/1» и «М99/9» снизился в 1,5 раза.

Для выявления наиболее активного из двух штаммов была определена их целлюлолитическая активность. Целлюлазная активность штаммов «М99/1» и «М99/9» определялась на 3-е, 6-е и 9-е сутки. Результаты исследования приведены на рисунке 3.

Химический состав вегетативной части топинамбура до и после биодеструкции

\begin{tabular}{l|c|c|c}
\hline \multirow{2}{*}{ Наименование показателя } & \multicolumn{3}{|c}{ Содержание, \% а.с.с. } \\
\cline { 2 - 4 } & субстрат 1 & субстрат 2 & субстрат 3 \\
\hline Минеральные вещества & $12,4 \pm 0,30$ & $16,1 / 11,8 \pm 0,30$ & $16,0 / 11,6 \pm 0,48$ \\
Вещества, экстрагируемые горячей водой & $36,7 \pm 0,52$ & $35,7 / 26,2 \pm 0,17$ & $33,9 / 24,8 \pm 0,48$ \\
Итого полисахаридов & 34,7 & $28,7 / 21,10$ & $30,3 / 21,90$ \\
Лигнин & $18,7 \pm 0,34$ & $19,3 / 14,1 \pm 0,90$ & $20,0 / 14,5 \pm 0,48$ \\
Убыль массы & - & 26,7 & 27,6 \\
\hline
\end{tabular}

Примечание. В знаменателе представлены показания с учетом убыли массы. 


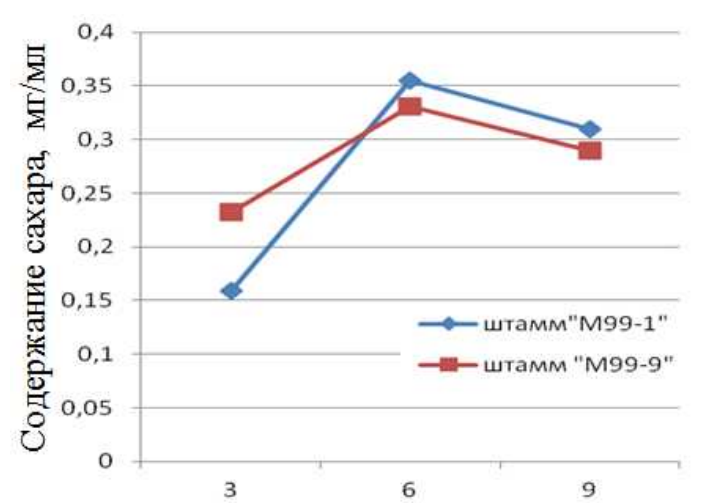

Продолжительность культивирования, сут
Рис. 3. Целлюлазная активность грибов рода Trichoderma штаммов «М99/1» и «М99/9»

Как видно из рисунка 3, целлюлазная активность грибов рода Trichoderma штаммов «М99/1» и «М99/9» сначала интенсивно растет (вплоть до 6-х суток), а затем начинает снижаться.

Наибольшее содержание сахара замечено у штамма «М99/1» на 6-е сутки, которое составляет 0,355 мг/мл. У штамма «М99/9» эта цифра на 6-е сутки равна 0,331 мг/мл.

При сравнении двух графиков видно, что их активность примерно одинакова, а критические точки приходятся на одни и те же сутки.

\section{Выводы}

В результате проделанной работы установлено, что по химическому составу вегетативная часть топинамбура представляет собой сложный комплекс веществ, позволяющий использовать его в качестве субстрата. Он на $36,7 \%$ представлен водорастворимыми веществами, в том числе доля углеводов в них составляет более $50 \%$, и на $34,7 \%$ - полисахаридами.

Наличие целлюлазной активности у гриба рода Trichoderma штаммов «М99/1» и «М99/9» позволяет использовать их для биоконверсии топинамбура.

Показано, что при продолжительности культивирования гриба рода Trichoderma штаммов «М99/1» и «М99/9» на исследуемом субстрате в течение 14-16 суток при температуре 27-28 ${ }^{\circ} \mathrm{C}$ утилизируется основная часть лигноуглеводного комплекса, убыль массы субстрата при этом составляет 26,7-27,6\%. Титр спор 1146109-1387109, что соответствует требованиям, предъявляемым к биопрепаратам.

\section{Список литературы}

1. Эйхе Э.П. Вопросы химии и биохимии топинамбура. М., 1976. 189 с.

2. Бобровник Л.Д. и др. Продукты профилактического питания на основе топинамбура. Одесса, 1988. 74 с.

3. Ченченко 3.А., Абовян 3.А., Ченченко С.С. Использование топинамбура в консервной промышленности. М., 1998. $29 \mathrm{c}$.

4. Рязанова Т.В., Чупрова Н.А., Исаева Е.В. Химия древесины: Ч. 1: Строение и свойства древесины. Экстрактивные вещества. Красноярск, 2011. 160 с.

5. Рязанова Т.В., Чупрова Н.А., Исаева Е.В. Химия древесины: Ч. 2: Основные компоненты древесины. Красноярск, 2011. 229 с.

6. Литовка Ю.А., Громовых Т.И. Биоконверсия растительного сырья. Красноярск, 2007. 100 с. 
Pikozina M.A. , Chuprova N.A., Ryazanova T.V. BIOCONVERSION OF THE VEGETATIVE PART OF JERUSALEM ARTICHOKE WITH FUNGI OF GENUS TRICHODERMA

Siberian State Technological Univerity, 82 Mira st, Krasnoyarsk, Russia, 660049 (Russia), e-mail: bioleif@yandex.ru

The results of the study of the process of bioconversion of the vegetative part of Jerusalem artichoke with fungi of genus Trichoderma asperellum of the strain of «M99/1» and «M99/9» are presented in the paper. It was shown change of the carbohydrate part of the Jerusalem artichoke in the process of biodegradation. It was revealed dynamic of titer of spores and decrease of mass as well as availability of cellulose activity of the studied strains. The carried out tests have clearly demonstrated the expediency of using the vegetative part of Jerusalem artichoke as substrate for the cultivation of fungi of the genus Trichoderma. The obtained results also allowed conducting a comparative characteristic of two new strains which were not studied previously with purpose to identify the most active.

Keywords: vegetative part, Jerusalem artichoke, Trichoderma.

\section{References}

1. Eikhe E.P. Voprosy khimii i biokhimii topinambura. [The chemistry and biochemistry of Jerusalem artichoke]. Moscow, 1976, 189 p. (in Russ.).

2. Bobrovnik L.D. et all. Produkty profilakticheskogo pitaniia na osnove topinambura. [Preventive nutrition products based on artichoke]. Odessa, 1988, 74 p. (in Russ.).

3. Chenchenko Z.A., Abovian Z.A., Chenchenko S.S. Ispol'zovanie topinambura v konservnoi promyshlennosti. [The use of artichoke in the canning industry]. Moscow, 1998, 29 p. (in Russ.).

4. Riazanova T.V., Chuprova N.A., Isaeva E.V. Khimiia drevesiny. Chast' 1. Stroenie i svoistva drevesiny. Ekstraktivnye veshchestva. [Wood Chemistry. Part 1. The structure and properties of wood. Extractives.]. Krasnoyarsk, 2011, 160 p. (in Russ.).

5. Riazanova T.V., Chuprova N.A., Isaeva E.V. Khimiia drevesiny. Chast' 2. Osnovnye komponenty drevesiny. [Wood Chemistry. Part 2. The main components of wood]. Krasnoyarsk, 2011, 229 p. (in Russ.).

6. Litovka Iu.A., Gromovykh T.I. Biokonversiia rastitel'nogo syr'ia. [Bioconversion of plant material]. Krasnoyarsk, 2007, 100 p. (in Russ.).

\footnotetext{
* Corresponding author.
} 
